\section{The rechargeable aluminum-ion battery}

\author{
N. Jayaprakash, S. K. Das and L. A. Archer* \\ Received 18th September 2011, Accepted 11th October 2011 \\ DOI: $10.1039 / \mathrm{c} 1 \mathrm{cc} 15779 \mathrm{e}$
}

\begin{abstract}
We report a novel aluminium-ion rechargeable battery comprised of an electrolyte containing $\mathrm{AlCl}_{3}$ in the ionic liquid, 1-ethyl3-methylimidazolium chloride, and $\mathrm{V}_{2} \mathrm{O}_{5}$ nano-wire cathode against an aluminium metal anode. The battery delivered a discharge capacity of $305 \mathrm{mAh}^{-1}$ in the first cycle and $273 \mathrm{mAh} \mathrm{g}^{-1}$ after 20 cycles, with very stable electrochemical behaviour.
\end{abstract}

Since the early 1990s, lithium ion batteries based on a carbonaceous material such as graphite as the anode, a lithiated metal oxide ( $\mathrm{LiMO}$, e.g. $\mathrm{LiCoO}_{2}$ ) cathode, and an aprotic liquid electrolyte have been the subjects of intense scientific and commercial interest for portable electronics applications. In recent years, the demand for secondary/rechargeable batteries with higher operating voltages, improved cycling stability, higher power densities, enhanced safety, and lower initial and life cycle costs has increased to meet new needs for smaller, lighter, more powerful electronic devices. Growing interest in hybrid electric vehicles (HEV) and plug-in hybrid electric vehicles (PHEVs) designed to simultaneously reduce dependence on fossil fuel-derived energy and to lower the carbon footprint of humans compounds the current need for advanced, cost-effective electrical energy storage technologies. ${ }^{1}$ Due to their high energy density and low self-discharge rate, Li-ion batteries are considered the most promising technology for meeting these demands for the foreseeable future. ${ }^{2-4}$

Aluminium is the most abundant metal and the third most abundant element in the earth's crust. An aluminium-based redox couple, which involves three electron transfers during the electrochemical charge/discharge reactions, provides competitive storage capacity relative to the single-electron Li-ion battery. ${ }^{5-7}$ Additionally, because of its lower reactivity and easier handling, such an aluminium-ion (Al-ion) battery might offer significant cost savings and safety improvements over the Li-ion battery platform. Aluminium has consequently long attracted attention as an anode in the Al-air battery because of its high theoretical Ampere-hour capacity and overall specific energy. ${ }^{8-11}$ Although these values are reduced in a practical battery because of the inability to operate aluminium and the air cathode at their thermodynamic potentials, and because water is consumed in the discharge reaction, the practical energy density still exceeds that of most commercially

School of Chemical and Biomolecular Engineering, Cornell University, Ithaca, New York 14853-5201 available rechargeable battery systems. ${ }^{12}$ The inherent hydrogen generation of the aluminium anode in aqueous electrolytes introduces additional limitations, which have been met by designing the batteries as reserve systems with the electrolyte added just before use, or as mechanically rechargeable batteries with the aluminium anode replaced after each discharge. Even with these adjustments, reliable electrically rechargeable aluminium/air batteries are considered unfeasible using aqueous electrolytes, due to the high corrosion and hydrogen evolution of aluminium in the electrolyte, which leads to a sharp reduction of the anodic efficiency. Furthermore, several studies have shown that in aqueous media $\mathrm{Al} /$ air batteries an oxide film covers the surface of the aluminium anode, which decreases the anodic voltage and cell efficiency. ${ }^{13}$ The literature is replete with studies investigating the suitability of ionic liquid-based electrolytes for electrodeposition of aluminium. ${ }^{14}$ A battery technology exploiting an Al-ion conducting ionic liquid electrolyte has been recently reported to show some promise. ${ }^{15}$

Herein, we report on a novel Al-ion battery system using $\mathrm{V}_{2} \mathrm{O}_{5}$ nano-wires as the cathode against an aluminium metal anode in an ionic liquid (IL), 1-ethyl-3-methylimidazolium chloride, -based electrolyte. ${ }^{16}$ To the best of our knowledge, the Al-ion battery configuration reported in this communication is the first to offer evidence of stable electrochemical behaviour with extended cycle life. We attribute these features to the synergistic effect of a suitable electrolyte, $\mathrm{V}_{2} \mathrm{O}_{5}$ nano-wire cathode and Al anode. Specifically, a key requirement for achieving high energy density of an Al-ion battery is an electrolyte having good ionic conductivity for $\mathrm{Al}^{3+}$, a wide electrochemical stability window in the presence of metallic aluminium, and which wets and permeates the pores of the metal oxide cathode. The apposite electrolyte should also exhibit reversible electrochemical deposition and dissolution of aluminium.

Based on the aforementioned studies of electrodeposition of aluminium in room temperature ILs, ${ }^{14} \mathrm{AlCl}_{3}$ dissolved in 1-ethyl-3-methylimidazolium chloride $([\mathrm{EMIm}] \mathrm{Cl})$ was used as the electrolyte in the current study to examine the operation of the Al-ion battery at room temperature $\left(25^{\circ} \mathrm{C}\right)$. This electrolyte possesses different degrees of Lewis acidity depending on the $[\mathrm{EMIm}] \mathrm{Cl}: \mathrm{AlCl}_{3}$ ratio, which provides an additional degree of freedom in tuning its properties. During discharge the prevalent $\mathrm{AlCl}_{4}{ }^{-}$anion in the electrolyte will react with the $\mathrm{Al}$ anode to form $\mathrm{Al}_{2} \mathrm{Cl}_{7}{ }^{-}$complex species, which reacts with the cathode to form an aluminium intercalated $\mathrm{V}_{2} \mathrm{O}_{5}$ discharge product. An acidic electrolyte composition with 1.1:1 molar 
ratio of $\mathrm{AlCl}_{3}$ to $([\mathrm{EMIm}] \mathrm{Cl})$ was found to yield effective electrochemical deposition and dissolution of aluminium and was therefore used for the study. To verify the role played by the $\mathrm{AlCl}_{3}-[\mathrm{EMIm}] \mathrm{Cl}$ electrolyte, electrochemical investigation of the same battery system was also performed with an electrolyte containing aluminium trifluromethanesulfonate (Al triflate) dissolved in a conventional aprotic liquid mixture $\mathrm{PC} / \mathrm{THF}(1: 1 \mathrm{v} / \mathrm{v})$. In contrast to the $\mathrm{AlCl}_{3}-[\mathrm{EMIm}] \mathrm{Cl}$ electrolyte system, no electrochemical activity was observed in the measured voltage range $-0.75-4.2 \mathrm{~V}$, underscoring the importance of the IL-based electrolyte.

The $\mathrm{V}_{2} \mathrm{O}_{5}$ nanowires used for the cathode were prepared by a hydrothermal method. ${ }^{17}$ In a typical synthesis, $0.364 \mathrm{~g}$ of commercial $\mathrm{V}_{2} \mathrm{O}_{5}$ powder (Sigma-Aldrich) and $30 \mathrm{ml}$ of DI $\mathrm{H}_{2} \mathrm{O}$ were mixed under vigorous magnetic stirring at room temperature, and then $5 \mathrm{ml} 30 \% \mathrm{H}_{2} \mathrm{O}_{2}$ (Sigma-Aldrich) was added to this mixed solution and kept continuously stirred for 30 min. Finally a transparent orange solution was obtained. The resultant solution was then transferred to a $40 \mathrm{ml}$ glass lined stainless steel autoclave and heated at $205^{\circ} \mathrm{C}$ for 4 days. The product was washed with anhydrous ethanol and distilled water several times. Finally, it was dried at $100{ }^{\circ} \mathrm{C}$ for $12 \mathrm{~h}$ and then annealed at $500{ }^{\circ} \mathrm{C}$ for $4 \mathrm{~h}$ in air. The synthesized product was characterized by Transmission Electron Microscopy (TEM, Tecnai, T12, $120 \mathrm{kV}$ ), powder X-ray diffraction (Scintage $\mathrm{X}$-ray diffractometer with $\mathrm{Cu} \mathrm{K} \alpha$ radiation), cyclic voltammetry (Solartron's Cell Test model potentiostat under the scan rate of $\left.0.2 \mathrm{mV} \mathrm{s}^{-1}\right)$, and galvanostatic electrochemical charge-discharge analysis (Maccor cycle life tester, under the potential window $2.5-0.02 \mathrm{~V})$.

The $\mathrm{V}_{2} \mathrm{O}_{5}$ cathode slurry was made by mixing $85 \%$ of the synthesized $\mathrm{V}_{2} \mathrm{O}_{5}$ nano-wires, $7.5 \%$ super-p carbon and 7.5\% of PVDF binder in NMP dispersant. Electrodes were produced by coating the slurry onto a 10 micron stainless steel current collector at $105{ }^{\circ} \mathrm{C}$ for $1 \mathrm{~h}$ initially and at $100{ }^{\circ} \mathrm{C}$ for $4 \mathrm{~h}$ in a vacuum oven. Since the acidic electrolyte used has the tendency to etch copper, stainless steel (301 type stainless steel, McMaster Carr, USA) was used as the current collector. The resulting slurry-coated stainless steel foil was roll-pressed and the electrode was reduced to the required dimensions with a punching machine. Preliminary cell tests were conducted on 2032 coin-type cells, which were fabricated in an argon-filled glove box $\left(\mathrm{AlCl}_{3}\right.$ is highly reactive), using 10 micron $\mathrm{Al}$ metal as the counter electrode and a Whatman glass microfiber separator. The electrolyte solution was 1.1:1 anhydrous $\mathrm{AlCl}_{3}$ in 1-ethyl-3-methylimidazolium chloride.

The phase purity and degree of structural order of the synthesized $\mathrm{V}_{2} \mathrm{O}_{5}$ was studied using a powder X-ray diffraction (XRD) pattern shown in Fig. 1a. The XRD obtained is in good agreement with the standard JCPDS pattern (File No. 89-0612) and shows the existence of phase pure orthorhombic $\mathrm{V}_{2} \mathrm{O}_{5}$ with Pmmn space group. The absence of any undesirable peaks demonstrates the presence of a phase pure product and the miller indices $(h k l)$ of all the characteristic peaks are marked as per the standard pattern. Fig. $1 \mathrm{~b}$ and c shows the transmission electron microscopy (TEM) image of the as synthesized $\mathrm{V}_{2} \mathrm{O}_{5}$ nano-wires. It is apparent that the synthesis procedure yields uniform and nearly monodispersed nanostructures having uniform diameters throughout their entire length and sharp, well-defined surfaces.
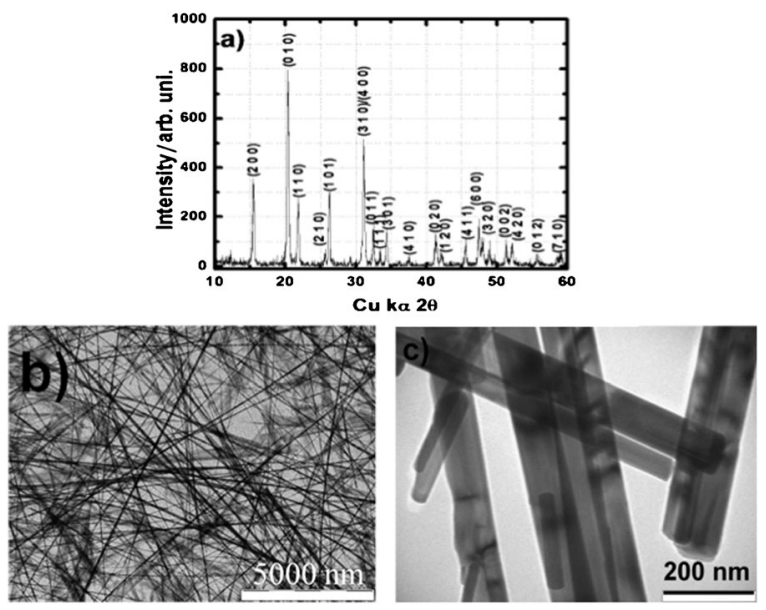

Fig. 1 (a) XRD pattern and (b, c) TEM images of the $\mathrm{V}_{2} \mathrm{O}_{5}$ nanowires used for the Al-ion secondary battery cathode.
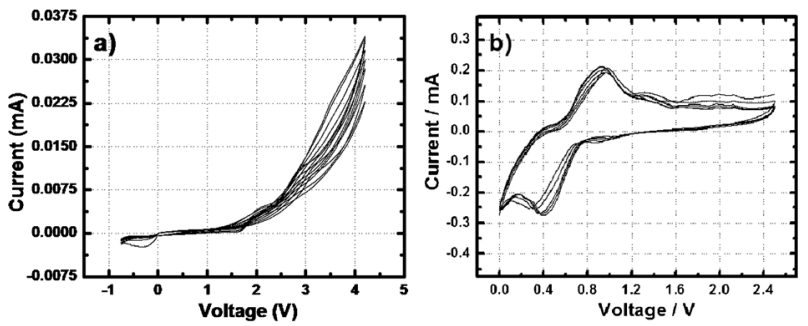

Fig. 2 Typical cyclic voltammograms of Al-ion battery using $\mathrm{V}_{2} \mathrm{O}_{5}$ nano-wire cathode and aluminium anode in (a) $1: 1 \mathrm{v} / \mathrm{v}$ of $\mathrm{Al}$ triflate in $\mathrm{PC} / \mathrm{THF}$ and (b) 1.1:1 molar ratio of $\mathrm{AlCl}_{3}$ in ([EMIm]Cl) at a sweep rate of $0.2 \mathrm{mV} \mathrm{s}^{-1}$.

To evaluate the feasibility of the electrolyte and the synthesized $\mathrm{V}_{2} \mathrm{O}_{5}$ nano-wires for Al-ion battery applications, electrochemical properties were examined by cyclic voltammetry and galvanostatic cycling analysis. Fig. $2 \mathrm{a}$ and $\mathrm{b}$ show the cyclic voltammograms of the $\mathrm{V}_{2} \mathrm{O}_{5}$ cathode against the $\mathrm{Al}$ metal anode in two different electrolytes: $1: 1 \mathrm{v} / \mathrm{v}$ of Al triflate in PC/THF (Fig. 2a) and 1.1:1 molar ratio of $\mathrm{AlCl}_{3}$ in ([EMIm]Cl) (Fig. 2b) at room temperature. As mentioned earlier, no electrochemical activity was observed for the Al-ion battery using Al triflate in PC/THF as the electrolyte and $\mathrm{V}_{2} \mathrm{O}_{5}$ nano-wire cathode in the measured voltage range of $-0.75-4.2 \mathrm{~V}$. On the other hand, a pair of cathodic and anodic peaks were observed for the Al-ion battery with $\mathrm{V}_{2} \mathrm{O}_{5}$ nano-wire cathode and $\mathrm{AlCl}_{3}$ in the [EMIm] Cl electrolyte under the potential window of $2.5-0.02 \mathrm{~V}$. The $\mathrm{CV}$ pattern shown in Fig. $2 \mathrm{~b}$ exhibited a cathodic peak at $\sim 0.45 \mathrm{~V}$ and a corresponding anodic peak at $\sim 0.95 \mathrm{~V}$, respectively, which may be attributed to the insertion/deinsertion of $\mathrm{Al}^{3+}$ ions into and from the orthorhombic crystal lattice structure of $\mathrm{V}_{2} \mathrm{O}_{5}$ nano-wires. Virtually no change in the peak position or peak current value was observed in the cyclic voltammogram shown in Fig. $2 \mathrm{~b}$ even after 20 scans, which substantiates the electrochemical stability of the battery. For this reason, $\mathrm{AlCl}_{3}$ in $[\mathrm{EMIm}] \mathrm{Cl}$ was chosen as the electrolyte for discharge/charge studies.

To further evaluate the electrochemical properties of the designed Al-ion battery, a galvanostatic discharge/charge reaction was performed at the cell voltage of $2.5-0.02 \mathrm{~V}$ at a constant current drain of $125 \mathrm{~mA} \mathrm{~g}^{-1}$. The open circuit voltage 

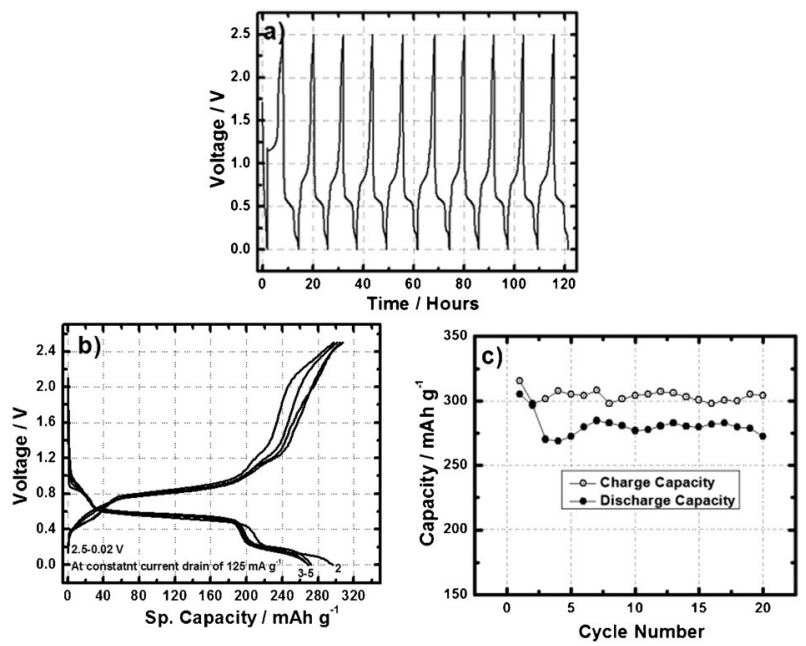

Fig. 3 (a) Voltage $v s$. time (b) voltage $v s$. sp. capacity and (c) cycle life plot of Al-ion battery containing aluminium anode, $\mathrm{V}_{2} \mathrm{O}_{5}$ nano-wire cathode in ionic liquid under the potential window $2.5-0.02 \mathrm{~V}$ and at a constant current drain of $125 \mathrm{~mA} \mathrm{~g}^{-1}$.

of the Al-ion battery was found to be $1.8 \mathrm{~V}$. Fig. 3a displays the voltage vs. time plot of the Al-ion battery, wherein no change in the potential of the $\mathrm{Al}^{3+}$ insertion/extraction plateau was observed. Fig. $3 \mathrm{~b}$ shows the voltage $v s$. capacity plot of the Al-ion battery which demonstrates a well defined and very stable $\mathrm{Al}^{3+}$ insertion plateau at $\sim 0.55 \mathrm{~V}$. In the first cycle, the battery exhibited an $\mathrm{Al}^{3+}$ ion insertion capacity of $305 \mathrm{mAh} \mathrm{g}^{-1}$ against $273 \mathrm{mAh} \mathrm{g}^{-1}$ at the end of 20 cycles. These values are somewhat lower than the theoretical capacity of $\mathrm{V}_{2} \mathrm{O}_{5}$ against the $\mathrm{Al}^{3+}$ ion, which is estimated to be $442 \mathrm{mAh} \mathrm{g}^{-1}$ considering a simple three electron transfer reaction (Al $+\mathrm{V}_{2} \mathrm{O}_{5} \leftrightarrow$ $\mathrm{AlV}_{2} \mathrm{O}_{5}$ ). Fig. $3 \mathrm{c}$ shows the galvanostatic cycling performance of the Al-ion battery, which nicely shows a high degree of reversibility and good capacity retention. The coulombic efficiency of the cell is not as high as would be needed for long-term practical use in a secondary battery, but its stability is quite encouraging. Significant crystallography and voltammetry studies are underway to understand intercalation of aluminium into $\mathrm{V}_{2} \mathrm{O}_{5}$ and other layered oxides. These studies will help shed light on the effect of variables such as the cell current density and electrolyte formulation on the coulombic efficiency and practical specific energy achievable in the Al-ion battery. Indeed based on the specific capacities observed experimentally, one might conclude that only about 0.7 moles of $\mathrm{Al}^{3+}$ ions participate in the actual redox reaction. As in the case of Li-ion secondary batteries, we anticipate significant opportunities for nanoscale engineering and chemical design of the Al-ion battery cathode to increase the overall cell potential. Additionally, we anticipate as significant efforts to pioneer ionic liquid and other Al-conducting electrolytes to enhance cell performance at high voltages and high current drains.

In conclusion, we report the first example of a functional Al-ion rechargeable battery. The battery uses $\mathrm{V}_{2} \mathrm{O}_{5}$ as the cathode against an aluminium metal anode in an ionic liquid-based electrolyte. When evaluated in galvanostatic cycling and cyclic voltammetry measurements, the battery displayed promising electrochemical features with stable cycling behaviour over 20 charge-discharge cycles. The theoretical energy density of the Al-ion battery with $\mathrm{V}_{2} \mathrm{O}_{5}$ as the cathode against aluminium metal as the anode was determined to be $240 \mathrm{Wh} \mathrm{kg}^{-1}$, which is not enough to power very much. But considering the other attractive attributes of an aluminium based secondary battery platform, the energy density of this first Al-ion cell is enough to initiate a global search for new materials and cell designs which we anticipate will lead to rapid and sustained improvements.

This publication was based on work supported in part by the Energy Materials Center at Cornell, an Energy Frontier Research Center funded by the U.S. Department of Energy, Office of Basic Energy Sciences, under Award Number DE-SC0001086, and by Award No. KUS-C1-018-02, made by King Abdullah University of Science and Technology (KAUST). Facilities available through the Cornell Center for Materials Research (CCMR) were also used for this study.

\section{Notes and references}

1 G. M. Whitesides and G. W. Crabtree, Science, 2007, 315, 796.

2 Y. K. Sun, S. T. Myung, B. C. Park, J. Prakash, I. Belharouak and K. Amine, Nat. Mater., 2009, 8, 320.

3 T. Zhang, N. Imanishi, Y. Shimonishi, A. Hirano, Y. Takeda, O. Yamamoto and N. Sammes, Chem. Commun., 2010, 46, 1661.

4 T. Ohzuku, M. Nagayama, K. Tsuji and K. Ariyoshi, J. Mater. Chem., 2011, 21, 10179.

5 Q. Li and N. J. Bjerrum, J. Power Sources, 2002, 110, 1.

6 X. Y. Ren, Battery Bimonthly, 1997, 27, 85.

7 J. Singer and W. L. Fielder, Am. Met. Mark., 2000, 108, 4.

8 M. L. Doche, F. N. Cattin, R. Durand and J. J. Rameau, J. Power Sources, 1997, 65, 197.

9 X. Y. Ren, Battery Bimonthly, 1997, 27, 85.

10 R. S. M. Patnaik, S. Ganesh, G. Ashok, M. Ganesan and V. Kapali, J. Power Sources, 1994, 50, 331.

11 E. J. Rudd and D. W. Gibbons, J. Power Sources, 1994, 47, 329.

12 D. Linden and T. B. Reddy, Handbook of Batteries, 3rd edn, 1995, McGraw-Hill.

13 Y. Tang, L. Lu, H. W. Roesky, L. Wang and B. Huang, J. Power Sources, 2004, 138, 313.

14 T. Jiang, M. J. Chollier Brym, G. Dubé, A. Lasia and G. M. Brisard, Surf. Coat. Technol., 2006, 201, 1.

15 M. P. Paranthaman, G. M. Brown, X. Sun, J. Nanda, A. Manthiram and A. Manivannan, Abstract \#314, 218th ECS Meeting.

16 S.K. Das and L.A. Archer, The Rechargeable Aluminum-ion battery, Cornell University Invention Disclosure, Docket \#5506.

17 T. Zhai, H. Liu, H. Li, X. Fang, M. Liao, L. Li, H. Zhou, Y. Koide, Y. Bando and D. Golberg, Adv. Mater., 2010, 22, 2547. 